\title{
Philosophiques
}

\section{Livres reçus (automne 2001)}

Volume 28, numéro 2, automne 2001

URI : https://id.erudit.org/iderudit/005672ar

DOI : https://doi.org/10.7202/005672ar

Aller au sommaire du numéro

Éditeur(s)

Société de philosophie du Québec

ISSN

0316-2923 (imprimé)

1492-1391 (numérique)

Découvrir la revue

Citer ce document

(2001). Livres reçus (automne 2001). Philosophiques, 28(2), 473-474.

https://doi.org/10.7202/005672ar

Ce document est protégé par la loi sur le droit d'auteur. L'utilisation des services d'Érudit (y compris la reproduction) est assujettie à sa politique d'utilisation que vous pouvez consulter en ligne.

https://apropos.erudit.org/fr/usagers/politique-dutilisation/
Cet article est diffusé et préservé par Érudit.

Érudit est un consortium interuniversitaire sans but lucratif composé de l’Université de Montréal, l'Université Laval et l'Université du Québec à Montréal. Il a pour mission la promotion et la valorisation de la recherche. https://www.erudit.org/fr/ 


\section{Livres reçus (automne 2001)}

Benoît, Jocelyn et Merlini, Fabio (éd.), Historicité et spatialité. Recherches sur le problème de l'espace dans la pensée contemporaine, Paris, Vrin (coll. "Problèmes et controverses »), 2001, 255 pages.

Cantin, Serge et Marger, Robert (dir.), L'autre de la technique. Perspectives multidisciplinaires. Québec, Presses de l'Université Laval — Paris, L'Harmattan, 2000, 339 pages.

Canto-Sperber, Monique, L'inquiétude morale et la vie humaine, Paris, PUF, 2001, 293 pages.

Chauviré, Christiane, Laugier, Sandra et Rosat, Jean-Jacques (éd.), Wittgenstein: Les mots de l'esprit. Philosophie de la psychologie, Paris, Vrin (coll. "Problèmes et controverses »), 2001, 384 pages.

Dokic, Jérôme et Engel, Pascal, Ramsey. Vérité et succès, Paris, PUF (coll. "Philosophies »), 2001, 127 pages.

Duns Scot, Traité du premier principe, Texte latin établi par W. Kluxen, traduit du latin par J.-D. Cavigioli, J.-M. Meilland et F.-X. Putallaz sous la direction de R. Imbach avec une introduction de F.-X. Putallaz, Paris, Vrin (coll. "Textes philosophiques »), 2001, 220 pages.

Lamoureux, Diane, L'amère patrie. Féminisme et nationalisme dans le Québec contemporain, Montréal, Les éditions du remue-ménage, 2001, 181 pages.

Lécrivain, André, Hegel et l'éthicité. Commentaire de la troisième partie des "Principes de la philosophie du droit ", Paris, Vrin (coll. "Bibliothèque d'histoire de la philosophie »), 2001, 174 pages.

Lisi, Francisco L., Plato's Laws and its Historical Significance. Selected papers of the International Congress on Ancient Thought - Salamanca, 1998, Sankt Augustin, Academia Verlag, 2001, 352 pages.

Losee, John, A Historical Introduction to the Philosophy of Science (Fourth Edition), New York, Oxford University Press, 2001, 314 pages.

Mattéi, Jean-François, Heidegger et Hölderlin. Le Quadriparti, Paris, PUF (coll. « Épiméthée »), 2001, 283 pages.

Marion, Jean-Luc, De surcrô̂t, Paris, PUF (coll. «Perspectives critiques »), 2001, 208 pages.

Marquet, Jean-François, Restitutions. Études d'histoire de la philosophie allemande, Paris, Vrin (coll. " Bibliothèque d'histoire de la philosophie »), 2001, 306 pages.

Narbonne, Jean-Marc, Hénologie, ontologie et Ereignis (Plotin - Proclus Heidegger), Paris, Les Belles Lettres (coll. «L'âne d'or »), 2001, 377 pages.

Ong-Van-Cung, Kim Sang, Descartes et l'ambivalence de la création, Paris, Vrin, (coll. "Philologie et Mercure »), 2001, 303 pages.

Robinson, Thomas M. et Brisson, Luc (éds.), Plato. Euthydemus, Lysis, Charmides. Proceedings of the V Symposium Platonicum of the Inter- 
national Plato Society held at the University of Toronto, 1998. Selected papers, Sankt Augustin, Academia Verlag, 2000, 412 pages.

Tully, James, Une étrange multiplicité. Le constitutionnalisme à une époque de diversité, Québec, Presses de l'Université Laval, 1999, 242 pages.

Vatter, Miguel E., Between Form and Event. Machiavelli's Theory of Political Freedom, Dordrecht/Boston/London, Kluwer Academic Publishers, 2000, 353 pages.

Outre les ouvrages qui apparaissent dans cette liste, la rédaction de Philosophiques peut obtenir, pour fin de compte-rendu, la plupart des livres publiés récemment aux Presses Universitaires de France, chez Vrin, au Seuil et à L'Harmattan.

Les personnes désireuses de faire un compte-rendu sont priées de s'adresser à :

Fabienne Pironet Université de Montréal Département de philosophie C.P. 6128 Succ. Centre-ville Montréal, Québec, H3C 3J7

Tél : (514) 343-7670 Télec : (514) 343-7899

Courriel : pironetf@philo.umontreal.ca 